\title{
Psychological health of caregivers of individuals with type 2 diabetes mellitus: A cross-sectional comparative study
}

\author{
Pankaj Jorwal, Rohit Verma ${ }^{1}$, Yatan Pal Singh Balhara ${ }^{2}$ \\ Departments of Medicine and ${ }^{1}$ Psychiatry, All India Institute of Medical Sciences, ${ }^{2}$ Department of Psychiatry, National Drug Dependence \\ Treatment Centre, All India Institute of Medical Sciences, New Delhi, India
}

\section{A B S T R A C T}

Introduction: The quality-of-life in individuals with diabetes is also dependent upon the quality of family relationships and general wellbeing of caregivers because the patient depends on them to uphold in the community. Only limited studies have assessed the psychological health of caregivers to individuals with diabetes. Aims and Objective: The current study aims at comparison of depression and anxiety levels among patients with diabetes and their caregivers. Materials and Methods: Fifty consecutive patients-care giver dyads of subjects having type 2 diabetes were recruited at an out-patient clinic of medicine at a tertiary care center.The dyads were assessed using a semistructured proforma for the socio-demographic details and for anxiety and depression levels using the Hospital Anxiety and Depression Scale (HADS). The data were analyzed using SPSS version 17.0. Correlation analysis was performed for multiple variables including blood glucose profile. Results: The mean duration of illness (4.93 \pm 3.53 years) and blood glucose parameters were not found to be associated to depressive or anxiety symptoms. Depressive and anxiety disorder was observed in $24 \%$ and $44 \%$ of patients and $10 \%$ and $18 \%$ of caregivers, respectively. Patients had significantly more HADS anxiety (HADS-A) scale scores than caregivers but not for HADS depression (HADS-D) scale. Female patients were found to be having more HADS-D scores than male patients $(P=0.02)$, but were not significantly different from caregivers. HADS-A scores were comparable among male and female gender in intragroup as well as intergroup comparison for patient and caregiver groups. Conclusion: Diabetes mellitus affects the psychological health of not only the patients but as well as the family caregivers and patients tend to be more anxious than the caregivers. Furthermore, it was seen that women with diabetes had higher rates of depression than their male counterparts.

Key words: Anxiety, caregiver, depression, diabetes, family

\section{INTRODUCTION}

Diabetes is one of the most common public health problems worldwide. The current estimates of almost 285 million individuals suffering from diabetes are expected to rise to 438 million by the year $2030 \cdot{ }^{[1]}$ Majority of these will reside in developing countries. The Indian estimates

\begin{tabular}{|l|l|}
\hline \multicolumn{2}{|c|}{ Access this article online } \\
\hline Quick Response Code: & Website: \\
\hline & www.joshd.net \\
\hline & \\
\hline & \\
\hline
\end{tabular}

of the prevalence of Type 2 diabetes mellitus vary from $8 \%$ to $15 \%$ among the urban population, with a significantly increasing trend over the years. ${ }^{[2]}$

Mental health disorders are well recognized to be coexisting with chronic illnesses. ${ }^{[3]}$ Compared to the general population, the risk of acquiring depression and anxiety is higher in individuals with diabetes. ${ }^{[3-5]}$

The quality-of-life (QOL) in individuals with diabetes is also dependent upon the quality of family relationships. ${ }^{[5]}$ Caregivers play an important role in supporting people with illness. This is of special relevance in the context of chronic disorders. It is important to explore caregiver's emotional turmoil as it helps in exploring their burden that can have an impact on the patient's illness and

Corresponding Author: Dr. Yatan Pal Singh Balhara, Department of Psychiatry, National Drug Dependence Treatment Centre, All India Institute of Medical Sciences, New Delhi, India. E-mail: ypsbalhara@gmail.com 
functioning apart from their own. The well-being of caregivers is important because the patients extensively depend on them.

Few studies have assessed the psychological health of caregivers to individuals with diabetes. ${ }^{[6-9]}$ The studies indicate higher burden in caregivers, ${ }^{[10]}$ proneness to depression, ${ }^{[9]}$ and poorer QOL. ${ }^{[9]}$ Anxiety and depressive symptoms in caregivers is also found to be associated with adolescent glycemic control. ${ }^{[11]}$ Researchers examining this issue have clearly stated that clinicians should be aware of such psychological problems in caregivers and intervene for better patient management. Studies report that enhancing social support improves disease management among adults with diabetes. ${ }^{[12,13]}$

The current study aimed at assessment of depression and anxiety levels among care givers of patients with diabetes being treated at out-patient department of tertiary care hospital. The levels of depression and anxiety were compared with that of the patients.

\section{MATERIALS ANd MethodS}

\section{Aim and objectives}

The current study aimed at assessment of depression and anxiety levels among caregivers of patients with diabetes being treated at out-patient department of tertiary care hospital. The levels of depression and anxiety were compared with that of the patients.

\section{Setting}

The study was conducted at an out-patient clinic of Department of Medicine at a Tertiary Care Hospital in India.

\section{Inclusion criteria}

The patients selected for the study were diagnosed with type 2 diabetes. Only those patient-care giver dyads giving informed consent for participation in the study were recruited for the study.

\section{Exclusion criteria}

Those patients or caregivers with any history of psychiatric illness (prior to diagnosis of diabetes in patient) were excluded from the study. In addition, patients (except for complications due to diabetes) and caregivers having any other comorbid medical illness were excluded from the study.

\section{Sample size}

Fifty consecutive patients-caregiver dyads were recruited in the study.

\section{Methodology}

Following inclusion in the study, patients and caregivers were assessed using a semi-structured proforma for the socio-demographic details. Subsequently, these dyads were assessed for anxiety and depression levels using the Hospital Anxiety and Depression Scale (HADS).

Hospital Anxiety and Depression Scale is a self-report questionnaire commonly used to assess levels of anxiety and depression. It was developed by Zigmond and Snaith ${ }^{[14]}$ in 1983. The HADS comprises statements, which the patients rate, based on their experiences over the past week. The 14 statements are relevant to generalized anxiety (7 statements) or "depression" (7 statements), the latter being large (but not entirely) composed of reflections of the state of anaerobia. Each question has four possible responses. Responses are scored on a scale from 3 to 0 . The maximum score is therefore 21 for depression and 21 for anxiety. The two subscales, HADS anxiety (HADS-A) and HADS depression (HADS-D), have been found to be independent measures. In its current form, the HADS is now divided into four ranges: Normal (0-7), mild (8-10), moderate (11-15) and severe (16-21).

The HADS questionnaire has been translated into many languages, and for many of these translations validation studies confirm the internationally applicable nature of this Questionnaire. ${ }^{[15]}$ It has been used in previous studies in Indian setting as well. ${ }^{[16-18]}$

\section{Data analysis}

The data were analyzed using SPSS version 21 (IBM Corp., Chicago, USA). Descriptive analysis was performed for socio-demographic profile. Independent sample t-test (for continuous variables) and Chi-square test (for categorical variables) were used to find the difference between the patients and the caregivers on different variables. In Cramer's V-test and Phi-test were used for $2 \times 4$ contingency tables. Persons correlation coefficient was used to ascertain the correlation between continuous variables. Linear regression model was used to explore the relation between anxiety/depression levels among the patients and anxiety/depression levels among caregivers. The level of statistical significance was kept at $P<0.05$.

The conditions of anonymity and confidentiality as specified in the institutional ethical guidelines were adhered to.

\section{RESULTS}

A total of 50 patient-care giver dyads were included in the study. The mean age was comparable for individuals with diabetes and their caregivers $(46.98 \pm 7.19$ years and 
$45.32 \pm 7.61$ years respectively, $P=0.26$ ). All subjects were married. The details of patient and caregiver sociodemographic profile are given in Table 1.

The primary earning member of the family was predominantly of male gender in both patient and caregiver group, although there was no significant difference among the groups. There were no overall significant differences among the groups on gender comparison over sociodemographic profile.

Female patients and caregivers were significantly less educated $(P<0.001)$ than their male counterparts [Table 2]. Belonging to male sex significantly correlated to being employed in both patient and caregiver groups $(r=0.66, P<0.0001 ; r=0.84, P<0.0001$ respectively). Similarly being the primary earning member of household was also significantly correlated to male sex in patient and caregiver groups $(r=0.61, P<0.0001 ; r=0.80$, $P<0.0001$ respectively). There was no other significant gender difference in both groups over parameters of age, family background, family type and socio-economic status.

The mean duration of illness in patient group was 4.93 \pm 3.53 years $(0.5-20)$ without any difference between males and females $(4.43 \pm 2.65$ and $5.35 \pm 4.13$ years, respectively). The duration of illness was not found to be associated to depressive or anxiety symptoms. The mean levels of fasting and post-prandial blood sugar were 154.29 $\pm 54.23 \mathrm{mg} / \mathrm{dl}$ and $230.84 \pm 68.28 \mathrm{mg} / \mathrm{dl}$ respectively in the patients. The mean glycated hemoglobin (HbA1c) levels were $9.18 \pm 1.69$. There was no significant gender difference in any of the blood sugar parameter in patient group [Table 3]. Sixty per cent of patients were on oral hypoglycemic agents alone, whereas $36 \%$ were also taking insulin.

Glycated hemoglobin levels were significantly correlated to fasting and post-prandial blood sugar levels $(r=0.66$, $P<0.0001$ and $r=0.70, P<0.0001$ respectively) but not to HADS-D and anxiety scale $(r=0.19, P=0.22, r=0.06$, $P=0.67$ respectively).
Depression Hospital Anxiety and Depression Scale scores were significantly correlated to HADS-A scores in both patient and caregiver groups $(r=0.72, P<0.0001 ; r=0.56$, $P<0.0001)$. Furthermore, a significant positive correlation was observed between anxiety scores of patients and depressive scores of care givers $(r=0.29, P=0.04)$.

About a third of the subject population in either group was without any depressive or anxiety disorder [Figure 1]. Among patients, depressive symptoms were present in $66 \%$ subjects, and $64 \%$ had anxiety symptoms, while $62 \%$ and $74 \%$ caregivers were found to be suffering from depressive and anxiety symptoms, respectively. None of the subjects of either group had severe depressive episode. The majority of subjects had mild symptoms of depression or anxiety except among patient population, where moderate anxiety symptoms were observed to be more prevalent [Table 4]. When including only moderate and severe symptoms, depressive episode was observed in $24 \%$ of patients and $10 \%$ of caregivers.

\begin{tabular}{|c|c|c|c|c|}
\hline Parameter & & $\begin{array}{c}\text { Patients } \\
\text { N (\%) }\end{array}$ & $\begin{array}{c}\text { Caregivers } \\
\text { N (\%) }\end{array}$ & $P$ value \\
\hline \multirow{2}{*}{ Gender } & Male & $23(46)$ & $27(54)$ & \multirow{2}{*}{0.43} \\
\hline & Female & $27(54)$ & $23(46)$ & \\
\hline \multirow[t]{3}{*}{ Marital status } & Married & $50(100)$ & 50 (100) & \multirow[t]{3}{*}{-} \\
\hline & Illiterate & $19(38)$ & $18(36)$ & \\
\hline & Primary & $3(6)$ & $2(4)$ & \\
\hline \multirow{3}{*}{ Education } & Secondary & - & $5(10)$ & \multirow[t]{3}{*}{0.24} \\
\hline & $\begin{array}{l}\text { Higher } \\
\text { secondary }\end{array}$ & $16(32)$ & $15(30)$ & \\
\hline & Graduate & $12(24)$ & $10(20)$ & \\
\hline \multirow{2}{*}{$\begin{array}{l}\text { Employment } \\
\text { status }\end{array}$} & Employed & $28(56)$ & 27 (54) & \multirow{2}{*}{0.84} \\
\hline & Unemployed & $22(44)$ & $23(46)$ & \\
\hline \multirow{2}{*}{$\begin{array}{l}\text { Family } \\
\text { background }\end{array}$} & Urban & $42(84)$ & $46(92)$ & \multirow[b]{2}{*}{0.22} \\
\hline & Rural & $8(16)$ & $4(8)$ & \\
\hline \multirow[t]{2}{*}{ Family type } & Nuclear & $39(78)$ & 39 (78) & \multirow{2}{*}{1.00} \\
\hline & Joint & $11(22)$ & $11(22)$ & \\
\hline \multirow{3}{*}{$\begin{array}{l}\text { Socio-economic } \\
\text { status }\end{array}$} & Lower & 27 (54) & $27(54)$ & \\
\hline & Middle & $20(40)$ & $21(42)$ & 0.89 \\
\hline & Upper & $3(6)$ & $2(4)$ & \\
\hline $\begin{array}{l}\text { Primary earning } \\
\text { member }\end{array}$ & & $27(54)$ & $30(60)$ & 0.34 \\
\hline
\end{tabular}

Table 2: Gender comparison of education as parameter among the patient and caregivers

\begin{tabular}{lcccccc}
\hline Group & \multicolumn{7}{c}{ Education } \\
\cline { 2 - 7 } & Illiterate & Primary & Secondary & Higher secondary & Graduate & $\boldsymbol{P}$ value \\
\hline Male patients & 2 & - & - & 9 & 12 & Phi $=0.73$ \\
Female patients & 17 & 3 & - & 7 & -0.69 \\
Male caregivers & 6 & - & - & 13 & - & $8<0.001$ \\
Female caregivers & 12 & 2 & 5 & 2 & $\mathrm{Phi}=0.64$ \\
\hline
\end{tabular}


Similarly, anxiety disorder was found in $44 \%$ of patients and $18 \%$ of caregivers.

Cramer's V-test and Phi-test for $2 \times 4$ contingency table revealed significant difference in HADS-A scale between patient and caregiver group, but not for HADS-D scale. Patient group had significantly more HADS-A scores than caregiver population (Phi $=0.385, P=0.002$ ), but the HADS-D scores were comparable among the groups [Table 4].

On gender comparison, female patients were found to be having more HADS-D scores than male patients $(P=0.02)$, but were not significantly different from caregivers. HADS-A scores were comparable among male and female gender in intragroup as well as intergroup comparison for patient and caregiver groups [Table 5].

\section{DISCUSSION}

The current cross-sectional study evaluated anxiety and depression levels among patients with type 2 diabetes and their caregivers in an out-patient setting.

The study sample had both the sexes equally represented in both groups. The mean duration of type 2 diabetes among the subjects was 4.93 (standard deviation \pm 3.53 ) years. The patient and caregiver dyads included in the study were

\begin{tabular}{|c|c|c|c|}
\hline $\begin{array}{l}\text { Blood Sugar } \\
\text { Parameter }\end{array}$ & $\begin{array}{c}\text { Male } \\
\text { Mean } \pm \text { SD }\end{array}$ & $\begin{array}{c}\text { Female } \\
\text { Mean } \pm \text { SD }\end{array}$ & $P$ value \\
\hline Fasting & $150.61 \pm 44.75$ & $151.37 \pm 53.93$ & 0.95 \\
\hline Post-prandial & $230.13 \pm 50.55$ & $223.56 \pm 70.71$ & 0.71 \\
\hline $\mathrm{HbA} 1 \mathrm{c}$ & $9.07 \pm 1.59$ & $9.14 \pm 1.68$ & 0.89 \\
\hline
\end{tabular}

comparable on different socio-demographic variables even on gender specific data except that males were found to be the primary earning member of the family irrespective of being a patient or a caregiver reflecting the usual Indian situation of a working male dominant society.

Our findings concur with other chronic disease models in having significant presence of psychological ill-health among patients and their caregivers. Majority of the subjects (about $2 / 3^{\text {rd }}$ of the patients and their caregivers) were found to be suffering from anxiety and depression, at the time of assessment. The prevalence of Depressive disorder and Generalized Anxiety Disorder were found to be $24 \%$ and $44 \%$ respectively in patients. Majority of the patients were suffering from mild levels of anxiety and depression (20\% and $42 \%$ respectively), and none had severe depression.

There are contradictory findings of prevalence of depression and anxiety among patients with type 2

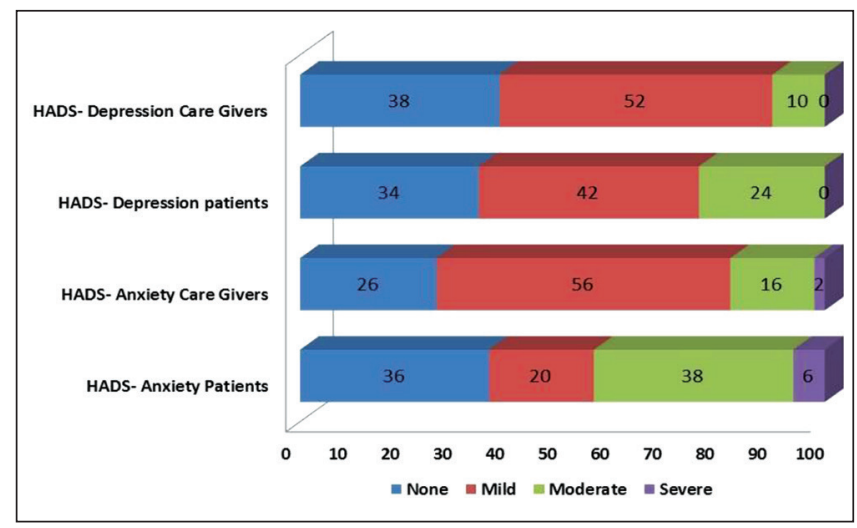

Figure 1: Distribution of scores on Hospital Anxiety and Depression Scale for patients and care givers

\begin{tabular}{|c|c|c|c|c|c|}
\hline Severity & None (0-7) (\%) & Mild (8-10) (\%) & Moderate (11-15) (\%) & Severe $(>16)(\%)$ & $P$ \\
\hline HADS anxiety patients & 36 & 20 & 38 & 6 & Phi $=0.385$ \\
\hline HADS anxiety caregivers & 26 & 56 & 16 & 2 & $\begin{array}{l}\text { Cramer's V }=0.385 \\
P=0.002\end{array}$ \\
\hline HADS depression patients & 34 & 42 & 24 & - & Phi $=0.188$ \\
\hline HADS depression caregivers & 38 & 52 & 10 & - & $\begin{array}{l}\text { Cramer's V }=0.188 \\
P=0.17\end{array}$ \\
\hline
\end{tabular}

HADS: Hospital Anxiety and Depression Scale

\begin{tabular}{|c|c|c|c|c|c|c|c|}
\hline \multirow[t]{2}{*}{ Participant } & \multirow[t]{2}{*}{ Parameter } & \multirow{2}{*}{$\begin{array}{c}\text { Male } \\
\text { mean } \pm \text { SD }\end{array}$} & \multirow{2}{*}{$\begin{array}{c}\text { Female } \\
\text { mean } \pm \text { SD }\end{array}$} & \multirow[t]{2}{*}{$\boldsymbol{P}$} & \multirow[t]{2}{*}{$t$} & \multicolumn{2}{|c|}{$95 \%$ confidence interval } \\
\hline & & & & & & Lower & Upper \\
\hline \multirow[t]{2}{*}{ Patients } & Anxiety & $8.87 \pm 4.21$ & $9.85 \pm 4.33$ & 0.42 & -0.80 & -3.42 & 1.45 \\
\hline & Depression & $7.48 \pm 2.79$ & $9.30 \pm 2.68$ & $0.02^{*}$ & -2.34 & -3.37 & -0.25 \\
\hline \multirow[t]{2}{*}{ Caregivers } & Anxiety & $8.56 \pm 2.88$ & $9.13 \pm 2.76$ & 0.47 & -0.71 & -2.91 & 1.04 \\
\hline & Depression & $7.52 \pm 1.86$ & $8.52 \pm 2.87$ & 0.14 & -1.48 & -2.36 & 0.35 \\
\hline
\end{tabular}

${ }^{\star} P<0.05 ;$ SD: Standard Deviation 
diabetes. The prevalence of depression was found to be $16.9 \%$ in one and $41 \%$ in other previous work from tertiary care hospital setting in India. ${ }^{[18,19]}$ The studies from Western countries also report the prevalence rates of both anxiety and depression to be lower. ${ }^{[4,20,21]}$ Collins et al $^{\left[{ }^{[21]}\right.}$ found the prevalence of depression and anxiety to be $32.0 \%$ and $22.4 \%$, respectively, as assessed by HADS in a cross-sectional study. ${ }^{[21]}$ In Malaysia, the prevalence of depression, anxiety and stress symptoms among Type II diabetics were $11.5 \%, 30.5 \%$ and $12.5 \%$ respectively. ${ }^{[22]}$

Conversely, several studies among diabetic patients had found higher rates. ${ }^{[23-25]}$ Khuwaja et al. ${ }^{[23]}$ reported the prevalence of depression and anxiety as $44 \%$ and $58 \%$, respectively, ${ }^{[23]}$ while another study reported rates as $48.27 \%$ and $55.10 \%$, respectively. ${ }^{[24]}$ On combining moderate and severe categories, $31 \%$ of participants reported clinically significant levels of depressive symptoms out of the $58 \%$ reporting of any depressive symptom in a study from Appalachian counties. ${ }^{[25]}$ A study in Qatar reported of mild and severe depression scores in diabetic cases to be $38.9 \%$ and $13.6 \%$ respectively and scores for mild and severe anxiety to be $37.7 \%$ and $35.3 \% .^{[26]}$

Duration of diabetes has also been found to be associated with a higher prevalence of depression. ${ }^{[27,28]}$ Chronic disease and disease duration were significantly associated with anxiety and depressive disorders in a study from Bahrain. ${ }^{[29]}$ However, no such association was observed between depression/anxiety and duration of diabetes and duration of treatment of diabetes in the current study. These findings were similar to that of Raval et al. who failed to find any significant association between duration of diabetes and depression. ${ }^{[18]}$ However, the mean duration of diabetes was lesser in our study (4 years) compared to previous study (10 years) ${ }^{[18]}$ Furthermore, one needs to consider the role of multiple modulators of the effect of duration of diabetes and the emergence of anxiety/depression.

We observed that female patients had significantly more depressive symptoms than male patients, but had comparable anxiety symptoms. Traditionally, female sex has been associated with higher rates of depression among the general population as well as those suffering from diabetes. ${ }^{[23,29-32]}$ A previous study by Roupa et al. ${ }^{[32]}$ reported that sex was strongly related to the occurrence of anxiety and depression symptoms with women appearing to have three times the percentages of anxiety and double the percentage of depression in comparison with men. ${ }^{[32]}$

There was no correlation of $\mathrm{HbA} 1 \mathrm{c}$, fasting or postprandial blood sugar levels to HADS-D or anxiety scales in patient population. Neither was is it observed on comparing male and female patients. Cross-sectional studies have found a significant positive correlation between depressive symptoms and $\mathrm{HbA} 1 \mathrm{c}$ in patients with Type 1 diabetes but no significant correlation in patients with Type 2 diabetes, ${ }^{[33-35]}$ giving rise to the hypothesis that the depression affects glycemic control in patients with Type 1, but not Type 2 diabetes. Although few crosssectional studies do report of poorer disease management and glycemic control in individuals with type 2 diabetes. ${ }^{[36]}$ A Dutch study also reported that depressive symptoms, but not anxiety is associated with glucose metabolism. ${ }^{[4]}$ The results of several prospective studies have been mixed. ${ }^{[37-39]}$

The prevalence of depressive disorder and generalized anxiety disorder was found to be $10 \%$ and $18 \%$ respectively in caregivers on combining moderate and severe scores. Although, the majority of caregivers were suffering from mild levels of depression and moderate levels of anxiety, none had severe depression.

Previous literature reports of significant prevalence of depression in caregivers similar to the current findings. ${ }^{[40]}$ Three studies evaluated caregivers of patients with diabetes only on the parameter of QoL and social functioning. ${ }^{\mid 6-8]}$ The only study evaluating mental health among caregivers of patients with diabetes reported the prevalence of $14 \%$ using Beck depression inventory. ${ }^{[9]}$ It was shown that caregivers of patients with type 2 diabetes mellitus were depressed, but not anxious, and the QOL of caregivers was not impaired statistically except for the social function. ${ }^{[9]}$

Caregivers involved in the care of individuals with chronic conditions tend to feel tired, isolated, and overwhelmed. Furthermore, some family caregivers who are employed report missing work, and even quitting or retiring early to provide care. ${ }^{[41]}$ Thus, chronic illness affects not only the lives of those suffering from the disease, but also those of family members who care for them. Existing studies document how caring for chronically ill family members or significant others at home influences multiple aspects of caregivers' lives. ${ }^{[40]}$

The importance of family stress theory in studying normative family transitions and adaptation to major life changes and illness is based on the central role that family strengths and capabilities play in understanding and explaining psychological and behavioral outcomes. ${ }^{[42]}$

We observed males to be significantly more educated and employed than females in both patient and caregiver groups. While depression or anxiety was not observed to be related to education or employment in patient 
group, it was seen that less educated caregivers had more depressive symptoms. Contrary to our study, which found comparable frequency of gender role as caregiver, in most studies the majority of caregivers have been reported to be a woman. ${ }^{[7-9,43,44]}$ Female caregivers, a daughter or spouse, generally have lower QoL and anxiety scores, but higher depression scores. ${ }^{[45]}$

Other studies in diabetes caregivers report that being employed or having a higher education is associated with better QOL quoting that working outside home may have a protective effect on the caregivers. ${ }^{[7,9,40]}$

We observed that the caregivers had comparable depressive as well as anxiety symptoms among the genders. Anaforoglu et al. ${ }^{[9]}$ also reported no significant difference among the genders for presence of any depressive or anxiety disorder. ${ }^{[9]}$ This may be delineating that the role of males and females in society as caregiver is equally shared and that gender dominance, generally observed in Indian society, does not seem to govern the fact that psychological problems could be higher in any one of them.

We observed that the patients had significantly more anxiety than caregivers but the rate of depression was similar. This warrants a cautious approach while dealing with patients and their caregivers as the co-morbid depression and anxiety might get ignored, owing to the usual notion of lower rates among them.

\section{Limitations and future directions}

There is limited literature that has explored the depressive and anxiety levels among care giver of individuals with diabetes form the country. The current study has certain limitations. First, we did not assess the effect of diabetes complications on the patient's or caregivers' psychological state. Second, the present study was performed crosssectionally in a relatively small group from a single center. Therefore, our findings may not represent those of the broader population. It would be interesting and insightful to prospectively follow up a larger cohort of patientcaregiver dyads in order to explore the association of various illness related factors and long-term outcome.

\section{CONCLUSION}

Diabetes mellitus affected the psychological health of not only the patients, but as well as the family caregivers and patients with type 2 diabetes tended to be more anxious than the caregivers. Furthermore, it was seen that women with diabetes had higher rates of depression than their male counterparts. Among caregivers, psychological health was comparable among both genders.

\section{REFERENCES}

1. World Health Organization. The Global Burden of Disease: 2004 Update. Geneva, Switzerland: World Health Organization; 2008.

2. Gupta R, Misra A. Type 2 diabetes in India: Regional disparities. Br J Diab Vasc Dis 2007;7:12-6.

3. Kruse J, Schmitz N, Thefeld W, German National Health Interview and Examination Survey. On the association between diabetes and mental disorders in a community sample: Results from the German National Health Interview and Examination Survey. Diabetes Care 2003;26:1841-6.

4. Bouwman V, Adriaanse MC, van 't Riet E, Snoek FJ, Dekker JM, Nijpels G. Depression, anxiety and glucose metabolism in the general dutch population: The new Hoorn study. PLoS One 2010;5:e9971.

5. Nouwen A, Winkley K, Twisk J, Lloyd CE, Peyrot M, Ismail K, et al. Type 2 diabetes mellitus as a risk factor for the onset of depression: A systematic review and meta-analysis. Diabetologia 2010;53:2480-6.

6. Brod M. Quality of life issues in patients with diabetes and lower extremity ulcers: Patients and care givers. Qual Life Res 1998;7:365-72.

7. Awadalla AW, Ohaeri JU, Al-Awadi SA, Tawfiq AM. Diabetes mellitus patients' family caregivers' subjective quality of life. J Natl Med Assoc 2006;98:727-36.

8. Awadalla AW, Ohaeri JU, Tawfiq AM, Al-Awadi SA. Subjective quality of life of outpatients with diabetes: Comparison with family caregivers' impressions and control group. J Natl Med Assoc 2006;98:737-45.

9. Anaforoglu I, Ramazanogullari I, Algün E, Kutanis R. Depression, anxiety and quality of life of family caregivers of patients with type 2 diabetes. Med Princ Pract 2012;21:360-5.

10. El-Mallakh P, Yates BE, Adkins S. Family caregiving for adults with schizophrenia and diabetes mellitus. Issues Ment Health Nurs 2013;34:566-77.

11. Cunningham NR, Vesco AT, Dolan LM, Hood KK. From caregiver psychological distress to adolescent glycemic control: The mediating role of perceived burden around diabetes management. J Pediatr Psychol 2011;36:196-205.

12. Miller CK, Davis MS. The influential role of social support in diabetes management. Top Clin Nutr 2005;20:157-65.

13. Cole I, Chesla CA. Interventions for the family with diabetes. Nurs Clin North Am 2006;41:625-39, vii.

14. Zigmond AS, Snaith RP. The hospital anxiety and depression scale. Acta Psychiatr Scand 1983;67:361-70.

15. Herrmann C. International experiences with the hospital anxiety and depression scale: A review of validation data and clinical results. J Psychosom Res 1997;42:17-41.

16. Verma R, Sharma S, Balhara YP, Mathur S. Anxiety and depression among caregivers of patients with Neurological IIIness. Delhi Psychiatry J 2011;14:120-3.

17. Balhara YP, Verma R, Sharma S, Mathur S. A study of predictors of anxiety and depression among stroke patient-caregivers J Midlife Health 2012;3:31-5.

18. Raval A, Dhanaraj E, Bhansali A, Grover S, Tiwari P. Prevalence \&amp; determinants of depression in type 2 diabetes patients in a tertiary care centre. Indian J Med Res 2010;132:195-200.

19. Balhara YP, Sagar R. Correlates of anxiety and depression among patients with type 2 diabetes mellitus. Indian J Endocrinol Metab 2011;15:S50-4.

20. Aina Y, Susman JL. Understanding comorbidity with depression and anxiety disorders. J Am Osteopath Assoc 2006;106 5 Suppl 2:S9-14.

21. Collins MM, Corcoran P, Perry IJ. Anxiety and depression symptoms in patients with diabetes. Diabet Med 2009;26:153-61. 
22. Kaur G, Tee GH, Ariaratnam S, Krishnapillai AS, China K. Depression, anxiety and stress symptoms among diabetics in Malaysia: A cross sectional study in an urban primary care setting. BMC Fam Pract 2013;14:69.

23. Khuwaja AK, Lalani S, Dhanani R, Azam IS, Rafique G, White F. Anxiety and depression among outpatients with type 2 diabetes: A multi-centre study of prevalence and associated factors. Diabetol Metab Syndr 2010;2:72.

24. Tovilla-Zárate C, Juárez-Rojop I, Peralta Jimenez Y, Jiménez MA, Vázquez S, Bermúdez-Ocaña D, et al. Prevalence of anxiety and depression among outpatients with type 2 diabetes in the Mexican population. PLoS One 2012;7:e36887.

25. de Groot M, Doyle T, Hockman E, Wheeler C, Pinkerman B, Shubrook J, et al. Depression among type 2 diabetes rural Appalachian clinic attendees. Diabetes Care 2007;30:1602-4.

26. Abdulbari B, Al-Hamaq AO, Dafeeah EE. High prevalence of depression, anxiety and stress symptoms among diabetes mellitus patients. Open Psychiatr J 2011;5:5-12.

27. Iype T, Shaji SK, Balakrishnan A, Charles D, Varghese AA, Antony TP. Cognition in type 2 diabetes: Association with vascular risk factors, complications of diabetes and depression. Ann Indian Acad Neurol 2009;12:25-7.

28. Perveen S, Otho MS, Siddiqi MN, Hatcher J, Rafique G. Association of depression with newly diagnosed type 2 diabetes among adults aged between 25 to 60 years in Karachi, Pakistan. Diabetol Metab Syndr 2010;2:17.

29. Almawi W, Tamim H, Al-Sayed N, Arekat MR, Al-Khateeb GM, Baqer A, et al. Association of comorbid depression, anxiety, and stress disorders with Type 2 diabetes in Bahrain, a country with a very high prevalence of Type 2 diabetes. J Endocrinol Invest 2008;31:1020-4.

30. Egede LE, Zheng D, Simpson K. Comorbid depression is associated with increased health care use and expenditures in individuals with diabetes. Diabetes Care 2002;25:464-70.

31. Mirza I, Jenkins R. Risk factors, prevalence, and treatment of anxiety and depressive disorders in Pakistan: Systematic review. BMJ 2004;328:794.

32. Roupa Z, Koulouri A, Sotiropoulou P, Makrinika E, Marneras X, Lahana I, et al. Anxiety and depression in patients with type 2 diabetes mellitus, depending on sex and body mass index. Health Sci J 2009;3:32-40.

33. Van Tilburg MA, McCaskill CC, Lane JD, Edwards CL, Bethel A, Feinglos MN, et al. Depressed mood is a factor in glycemic control in type 1 diabetes. Psychosom Med 2001;63:551-5.

34. Ciechanowski PS, Katon WJ, Russo JE, Hirsch IB. The relationship of depressive symptoms to symptom reporting, self-care and glucose control in diabetes. Gen Hosp Psychiatry 2003;25:246-52.
35. Surwit RS, van Tilburg MA, Parekh PI, Lane JD, Feinglos MN Treatment regimen determines the relationship between depression and glycemic control. Diabetes Res Clin Pract 2005;69:78-80.

36. De la Roca-Chiapas JM, Hernández-González M, Candelario M, Villafaña Mde L, Hernández E, Solorio S, et al. Association between depression and higher glucose levels in middle-aged Mexican patients with diabetes. Rev Invest Clin 2013;65:209-13.

37. Katon WJ, Von Korff M, Lin EH, Simon G, Ludman E, Russo J, et al. The pathways study: A randomized trial of collaborative care in patients with diabetes and depression. Arch Gen Psychiatry 2004;61:1042-9.

38. van der Ven NC, Hogenelst MH, Tromp-Wever AM, Twisk JW, van der Ploeg HM, Heine RJ, et al. Short-term effects of cognitive behavioural group training (CBGT) in adult Type 1 diabetes patients in prolonged poor glycaemic control. A randomized controlled trial. Diabet Med 2005;22:1619-23.

39. Georgiades A, Zucker N, Friedman KE, Mosunic CJ, Applegate $\mathrm{K}$, Lane JD, et al. Changes in depressive symptoms and glycemic control in diabetes mellitus. Psychosom Med 2007;69:235-41.

40. Lim JW, Zebrack B. Caring for family members with chronic physical illness: A critical review of caregiver literature. Health Qual Life Outcomes 2004;2:50.

41. Rorer E. United Hospital Fund Study Finds Changes in Nation's Health Care System Place Daunting New Burdens on 25 Million Unpaid Family Caregivers Who Provide Nearly \$200 Billion in Essential Services. New York; 1998.

42. Figley CR. Treating Stress in Families. New York: Brunner/ Mazel; 1989.

43. Han B, Haley WE. Family caregiving for patients with stroke. Review and analysis. Stroke 1999;30:1478-85.

44. Haley WE, LaMonde LA, Han B, Burton AM, Schonwetter R. Predictors of depression and life satisfaction among spousal caregivers in hospice: Application of a stress process model. J Palliat Med 2003;6:215-24.

45. Li TC, Lee YD, Lin CC, Amidon RL. Quality of life of primary caregivers of elderly with cerebrovascular disease or diabetes hospitalized for acute care: Assessment of well-being and functioning using the SF-36 health questionnaire. Qual Life Res 2004;13:1081-8.

How to cite this article: Jorwal P, Verma R, Balhara YS. Psychological health of caregivers of individuals with type 2 diabetes mellitus: A cross-sectional comparative study. J Soc Health Diabetes 2015;3:95-101.

Source of Support: Nil. Conflict of Interest: None declared. 